EDITORIAL

\title{
FORMACIÓN CONTINUADA EN METODOLOGÍA DE INVESTIGACIÓN Y DOCUMENTACIÓN. JORNADA JASPE 2019
}

\section{Continuous training in research methodology and documentation. JAsPE 2019 Conference}

José Luis PARDAL-REFOYO

Hospital Universitario de Salamanca. Servicio de Otorrinolaringología y Cirugía de Cabeza y Cuello. Salamanca. España

Director de Revista ORL. Ediciones Universidad de Salamanca

Correspondencia: jlpardal@usal.es

Fecha de publicación: 13 de julio de 2019

Fecha de publicación del fascículo: 1 de septiembre de 2019

Conflicto de intereses: Los autores declaran no tener conflictos de intereses

Imágenes: Los autores declaran haber obtenido las imágenes con el permiso de los pacientes

Política de derechos y autoarchivo: se permite el autoarchivo de la versión post-print (SHERPA/RoMEO)

Licencia CC BY-NC-ND. Licencia Creative Commons Atribución-NoComercial-SinDerivar 4.0 Internacional

Universidad de Salamanca. Su comercialización está sujeta al permiso del editor

Revista ORL nació en 2010 como medio abierto para la difusión del conocimiento de la Otorrinolaringología y Cirugía de Cabeza y Cuello. Desde el inicio del proyecto se consideró que debería ser además un medio que facilitase el acceso a contenidos de metodología de investigación y documentación relacionada con la Otorrinolaringología. Los grandes cambios en las modalidades editoriales, sistemas de edición, almacenamiento y difusión del conocimiento han modificado las formas con las que los autores deben afrontar el proceso de elaboración y publicación de sus informes de investigación.

Revista ORL (inicialmente Revista de la Sociedad Otorrinolaringológica de Castilla y León, Cantabria y La Rioja) tiene la vocación de facilitar tanto la publicación como de ayudar a los autores a adquirir y mantener actualizados sus conocimientos en metodología y documentación. Por este motivo desde 2013 se organizan jornadas de formación en estas áreas de conocimiento, inicialmente orientadas al proceso de edición y progresivamente hacia conocimientos más específicos. 


\section{FORMACIÓN CONTINUADA EN METODOLOGÍA DE INVESTIGACIÓN Y DOCUMENTACIÓN. JORNADA JASPE 2019 \\ PARDAL-REFOYO JL}

El 18 de enero de 2016 firmamos el Convenio Básico de Colaboración Institucional entre la Sociedad Otorrinolaringológica de Castilla y León, Cantabria y La Rioja y la Universidad de Salamanca precisamente para fomentar la colaboración y la formación en todas las áreas de conocimiento relacionadas con la investigación.
Esta colaboración ha dado sus frutos. Cada septiembre organizamos la Jornada JAsPE (Jornadas de Actualización sobre el Proceso Editorial), a lo largo del año organizamos cursos sobre documentación y metodología en formato de cuatro horas y al menos una vez al año, una sesión de lectura crítica.

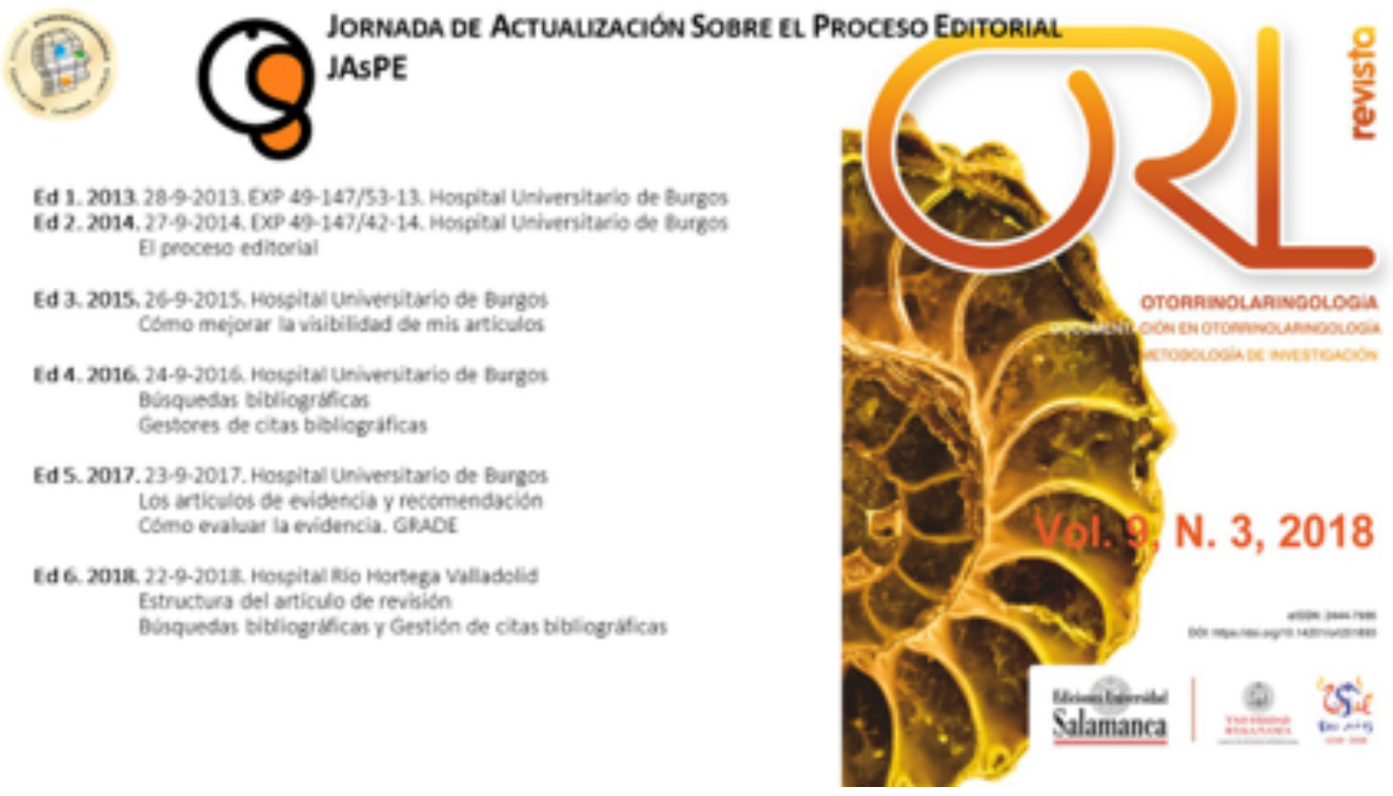

JORNADA DE ACTUALIZACIÓN SOBRE EL PROCESO EDITORIAL (JASPE) 2019 $7^{\text {a }}$ EDICIÓN

Salamanca. Facultad de Medicina.

La jornada consta de cuatro cursos prácticos a los que los asistentes pueden inscribirse por separado

- Gestión de bibliografía y citas bibliográficas con Mendeley. $3^{a}$ edición

(19-sep-2019, 9-13,30)

- Metodología de la investigación en ciencias de la salud, nivel 0. 2a edición (19-sep-2019, 16.30-20.30)

- La búsqueda bibliográfica paso a paso $4^{\text {a }}$ edición (20-sep-2019, 9 a 13.30h)

- La revisión sistemática paso a paso: de la pregunta a la evaluación GRADE (20-sep-201916.30 a 20.30h) 


\section{FORMACIÓN CONTINUADA EN METODOLOGÍA DE INVESTIGACIÓN Y DOCUMENTACIÓN. JORNADA JASPE 2019 \\ PARDAL-REFOYO JL}

Este año 2019 hemos organizado dos jornadas con cuatro cursos prácticos en horario de mañana y tarde en formato de cuatro horas con el objetivo común de incrementar los conocimientos necesarios para proyectar y realizar un artículo de revisión sistemática.

Por ello nos hemos centrado en adquirir las habilidades para la gestión de la bibliografía con Mendeley, en cómo realizar una búsqueda bibliográfica eficiente y eficaz, en revisar los aspectos metodológicos básicos necesarios en la investigación (nivel 0) y en cómo realizar la revisión sistemática paso a paso, desde cómo diseñar la pregunta de investigación a como evaluar el nivel de evidencia y calidad de los artículos revisados con el método GRADE.

Revista ORL y Ediciones Universidad de Salamanca apuestan por el acceso abierto al conocimiento científico según las directrices del Grupo de Editores de Revistas Españolas sobre Ciencias de la Salud (GERECS) y por mejorar y adecuar la evaluación de la producción científica de los investigadores según el documento de la Declaración de San Francisco (DORA).

Invitamos a todos a participar con su presencia $\mathrm{y}$ con ideas que nos ayuden a mejorar.

Gracias por colaborar con Revista ORL.

\section{REFERENCIAS}

- Convenio Básico de Colaboración Institucional entre la Sociedad Otorrinolaringológica de Castilla y León, Cantabria y La Rioja y la Universidad de Salamanca. Disponible en: https:// docs.wixstatic.com/ugd/62037a_d598d5b7a7bd43b7b55eaeae7aea9ff3.pdf

- Declaration-on-Research-Assessment DORA, Pardal-Peláez B. Declaración de San Francisco sobre la evaluación de la investigación. Revista ORL [Internet]. 1 Dic 2018 [citado 13 Jul 2019]; 9(4): 295-299. Disponible en: http://revistas.usal. es/index.php/2444-7986/article/view/17845 DOI: http://dx.doi.org/10.14201/orl.17845
- Declaration-on-Research-Assessment DORA, Pardal-Peláez B. San Francisco Declaration on Research Assessment. Revista ORL, Salamanca, v. 9, n. 4, p. 295-299, dec. 2018. ISSN 24447986. Available at: <http://revistas.usal.es/index. php/2444-7986/article/view/orl.17845>. Date accessed: 13 Jul. 2019. doi:10.14201/orl.17845. DOI: http://dx.doi.org/10.14201/orl.17845

- Ediciones Universidad de Salamanca. Enlace: http:// www.eusal.es/

- Ediciones Universidad de Salamanca. Revistas. Enlace: http://revistas.usal.es/

- Ferreras-Fernández T. Revista ORL en el Ecosistema de la Ciencia Abierta. Revista ORL [Internet]. 1 Jun 2018 [citado 13 Jul 2019]; 9(6): 1.7. Disponible en: http://revistas.usal.es/index.php/24447986/article/view/18330 DOI: http://dx.doi. org/10.14201/orl.18330

- Formación JAsPE. Enlace: https://www.sociedadorl. com/jaspe-formacion

- Merlo-Vega J, Ferreras-Fernández T. Colaboración Bibliotecas de la USAL y Sociedad Otorrinolaringológica de Castilla y León, Cantabria y La Rioja. Revista ORL [Internet]. 15 Ene 2016 [citado 13 Jul 2019]; 7(1): 65-66. Disponible en: http://revistas. usal.es/index.php/2444-7986/article/view/13875 DOI: http://dx.doi.org/10.14201/orl.13875

- Ochoa-Sangrador C. Evidencia y recomendación. Revista ORL [Internet]. 9 Mar 2016 [citado 13 Jul 2019]; 7(2): 67-71. Disponible en: http://revistas. usal.es/index.php/2444-7986/article/view/14019 DOI: http://dx.doi.org/10.14201/orl.14019

- Pardal-Refoyo J. Nota del editor. Búsqueda y gestión de la bibliografía. Revista ORL [Internet]. 15 Oct 2016 [citado 13 Jul 2019]; 7(4): 245-246. Disponible en: http://revistas.usal.es/index.php/24447986/article/view/15154 DOI: http://dx.doi. org/10.14201/orl.15154

- Pardal-Refoyo J. Nota del editor. Gestión del proceso editorial y formación permanente. Revista ORL[Internet]. 3 Jul 2016 [citado 13 Jul 2019]; 7(3): 185-187. Disponible en: http://revistas.usal. 
FORMACIÓN CONTINUADA EN METODOLOGÍA DE INVESTIGACIÓN Y DOCUMENTACIÓN.

JORNADA JASPE 2019

PARDAL-REFOYO JL

es/index.php/2444-7986/article/view/14853 DOI: http://dx.doi.org/10.14201/orl.14853

- Pardal-Refoyo, J.L., Azofra, E., Ferreras, T., Martín, H., Redero, Á. (2017). Nuevas vías de publicación para revistas biomédicas. Proyecto Revista ORL de Ediciones Universidad de Salamanca. Ponencia presentada en el Congreso Ecosistemas del Conocimiento Abierto (ECA 2017). Salamanca. http:// hdl.handle.net/10366/135631 https://gredos.usal. es/handle/10366/135562
- Revista ORL. Enlace: www.revistaorl.com

- Sanz-Valero J. Declaración de Sant Joan d'Alacant en defensa del acceso abierto a las publicaciones científicas, del Grupo de Editores de Revistas Españolas sobre Ciencias de la Salud (GERECS). Revista ORL [Internet]. 1 Dic 2018 [citado 13 Jul 2019]; 9(4): 287-290. Disponible en: http:// revistas.usal.es/index.php/2444-7986/article/ view/17318 DOI: http://dx.doi.org/10.14201/ orl.17318 